\title{
Decentralized controller gain scheduling using PSO for power system restoration assessment in a two-area interconnected power system
}

\author{
R. Jayanthi ${ }^{1}$, , A. A. Chidambaram ${ }^{2}$, C. Banusri ${ }^{3}$ \\ ${ }^{1 *}$ Department of Electrical Engineering, Annamalai University, Annamalainagar -608002, INDIA \\ ${ }^{2}$ Department of Electrical Engineering, Annamalai University, Annamalainagar -608002, INDIA \\ ${ }^{3}$ Department of Electrical Engineering, Jaya College of Engineering, Avadi, Chennai. INDIA \\ *Corresponding Author: e-mail: rrj_pavi@yahoo.co.in, Tel +91-4144-237092
}

\begin{abstract}
Load Frequency Control (LFC) is one of the most important issues in electrical power system design/operation and is becoming much more significant recently with increasing size, changing structure and complexity in restoration of interconnected power systems. In practice, LFC systems are used with simple Proportional-Integral (PI) or Integral (I) controllers. However, since the PI or I control parameters are usually tuned based on classical or trial-and-error approaches, they are incapable of obtaining good dynamic performance if the power system is more vulnerable due to various load changing scenarios in multi-area power system. For this reason, in this study the P and I control parameters are tuned based on Particle Swarm Optimization (PSO) algorithm for a better Load-Frequency Control in a Two-Area Two-Unit Thermal Reheat Power System (TATURIPS) with step load perturbation. To exemplify the optimum parameter search PSO is used as it is an optimization method, therefore, even in the uncertainty area of controller parameters, finds the best parameters for controller and obtained controller is an optimal controller. This makes a trade-off between exploration and exploitation of search space to find global optimum in less number of generations. A TATURIPS is taken for the study to illustrate the proposed method. To show effectiveness of proposed method, the performance of optimized PI controller is obtained with several time-domain simulations for various load changes scenarios and is presented. Simulation results emphasis on the better settling time based stability performance of optimized PI controller in the TATURIPS with GT unit when compared with that of the SMES and the conventional system two-unit two-area interconnected power systems.
\end{abstract}

Keywords: Load Frequency Control, Particle Swarm Optimization, TATURIPS, Gas Turbine, Super Conducting Magnetic Energy Storage Device.

\section{Introduction}

Large-scale power systems are normally composed of interconnected subsystems or control areas. The connection between the control areas is done using tie-lines. Each area has its own generator or group of generators and it is responsible for its own load and scheduled interchanges with neighboring areas. Because loading of a given power system is never constant and to ensure the quality of power supply, a load frequency controller is needed to maintain the system frequency at the desired nominal value. It is known that changes in real power affect mainly the system frequency and the input mechanical power to generators is used to control the frequency of the output electrical power. In a conventional power system, each control area contains different kinds of uncertainties and various disturbances due to increased complexity, system modeling errors and changing power system structure. A well designed power system should not only cope up with changes in load but also with system disturbances and it should provide acceptable high level of power quality while maintaining both voltage and frequency within tolerable limits (Wang Y, et al, 1998). During the last three decades, various control strategies for LFC have been proposed. This extensive research is due to the fact that LFC constitutes an important function on power system operation where the main objective is to regulate the output power of each generator at prescribed levels while keeping the frequency fluctuations within pre-defined limits. Robust adaptive 
control schemes have also been developed (Yamashita. et al, 1991, Pan et al., 1989, Aldeen et al., 1991) to deal with changes in system parametric under LFC strategies. Viewing a multi-area power system under LFC as a decentralized control design for a multi-input multi output system, it has been shown that a group of local controllers with tuning parameters can guarantee the overall system stability and performance. The result reported in Lim et al. (1996) demonstrates clearly the importance of robustness and stability issues in LFC design. The applications of artificial neural networks, genetic algorithms, fuzzy logic and optimal control to LFC have been reported in (Shayegi et al, 2007, Shayeghi. et al., 2007, Chao ou, et al, 2006). The objective of this study is to investigate the load frequency control, of a multi-area power system taking into consideration of various level of step sized loading to assess the requirements for power system restoration. An optimal control scheme based particle swarm optimization (PSO) Algorithm method is used for tuning the parameters of PI controller (S.P. Ghoshal, 2004). The proposed controller is simulated for a two-area two-unit thermal reheat power system and the output responses of the system with respect to the settling time has been studied. To show the effectiveness of proposed method and also to compare the performance of these two controllers, several changes in demand of first area, demand of second area and demand of two areas simultaneously are applied. Simulation results indicate that controllers designed using PSO approach guarantees good performance under various load conditions. The expert system, which is used to bring up the vulnerable power system to a normal system which allows the estimation and observation of the real restoration time, the degree of stability, the observation of the system voltage profile, power to be transmitted can be done using the following tools (Adibi et al., 1994).

1.1Generation Management: This tool is responsible for making the generators to commit for the optimal generation. Firstly, it started by finding the smallest black start generator in the solution and then it connects the generators in accordance with the generator sequence provided by the PSO solution.

1.2Restoration Path Management: In every step of connecting a generator or load, an optimized path algorithm is used to find the shortest path. Moreover the Path Management is used to check the loading limits of every line proposed for connection.

1.3 Time Management: Since one of the main goals of using the expert system is to estimate the real restoration time, great attention has been given to the time required for every element in every stage of restoration.

1.4 Load management: During restoration, loads are restored based on the load priorities and system security considerations. The priorities of loads are calculated in accordance to the load importance. If two loads are in the same degree of priority, the nearest one is picked. Moreover, if two or more loads are in the same degree of priority and in the same distance, the load with the highest level of connectivity is picked.

1.5 Role of expert system in this proposed work: The main objectives of expert system in knowledge based restoration are

- By providing initial source of power immediately to the interconnected power system with SMES unit.

- By optimizing the gain values of the PI controller using PSO technique for the two-area interconnected power system with SMES unit for system restoration.

- The primary function of the expert system is to restore the interconnected thermal reheat power system even for small disturbances and to avoid excess under frequency deviations.

\section{Modeling of a two-area interconnected thermal reheat power system}

Due to the inherent characteristics of changing loads, the operating point of power system may change very much during a daily cycle. The generation changes must be made to match the load perturbation at the nominal conditions, if the normal state is to be maintained. The mismatch in the real power balance affects primarily the system frequency but leaves the bus voltage magnitude essentially unaffected. In a power system, it is desirable to achieve better frequency constancy than obtained by the speed governing system alone. This requires that each area should take care of its own load changes, such that schedule tie power can be maintained. A two-area interconnected system dynamic model in state variable form can be conveniently obtained from the transfer function model. Figure 1 represents the transfer function model of a two-area reheat thermal system.

The state variable equation of the minimum realization model of the ' $\mathrm{N}$ ' area interconnected power system is expressed as (Chidambaram et al., 2005).

$$
\begin{aligned}
& \dot{X}=\mathrm{Ax}+\mathrm{Bu}+\Gamma \mathrm{d} \\
& \mathrm{Y}=\mathrm{Cx}
\end{aligned}
$$

Where, the system state vector $\mathrm{x}$ consists of the following variables as:

$$
\begin{array}{r}
{[x]=\left[\int \mathrm{ACE}_{1} d t, \int A C E_{2} d t, \Delta F_{1}, \Delta P_{g 1}, \Delta X_{e 1}, \Delta P_{t i e}, \Delta F_{2}, \Delta P_{g 2}, \Delta X_{e 2}\right]^{T}} \\
\mathrm{u}=\left[\mathrm{u}_{1}, \ldots ., \mathrm{u}_{\mathrm{N}}\right]^{\mathrm{T}}=\left[\Delta \mathrm{P}_{\mathrm{c} 1}, \ldots, \Delta \mathrm{P}_{\mathrm{cN}}\right]^{\mathrm{T}} \quad \mathrm{N}-\text { Control input vector }
\end{array}
$$




$$
\begin{array}{ll}
\mathrm{d}=\left[\mathrm{d}_{1}, \ldots . \mathrm{d}_{\mathrm{N}}\right]^{\mathrm{T}}=\left[\Delta \mathrm{P}_{\mathrm{D} 1}, \ldots, \Delta \mathrm{P}_{\mathrm{DN}}\right]^{\mathrm{T}} & \mathrm{N}-\text { Disturbance input vector } \\
\mathrm{y}=\left[\mathrm{y}_{1}, \ldots, \mathrm{y}_{\mathrm{N}}\right]^{\mathrm{T}} & 2 \mathrm{~N}-\text { measurable output vector }
\end{array}
$$

$\mathrm{A}$ is system matrix, $\mathrm{B}$ is the input distribution matrix and $\Gamma$ disturbance distribution matrix, $\mathrm{x}$ is the state vector, $\mathrm{u}$ is the control vector and $\mathrm{d}$ is the disturbance vector of load changes of appropriate dimensions.

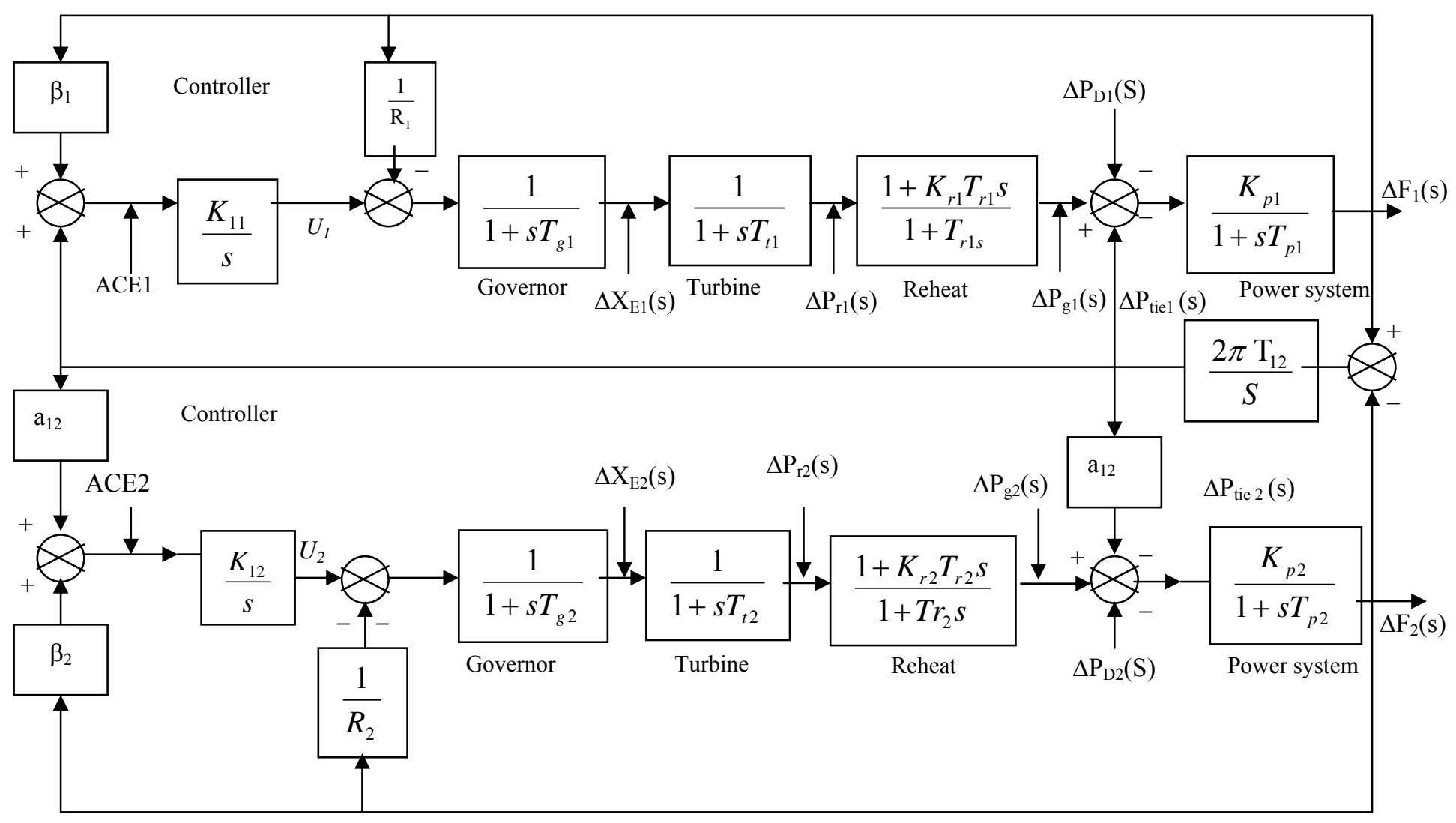

Figure 1. Transfer function model of two-area reheat thermal system

The typical values of system parameters for nominal operation condition are given in appendix. This study focuses on optimal tuning of controllers for LFC and tie-power control with settling time based optimization using PSO algorithm to ensure a better power system restoration assessment. The aim of the optimization is to search for the optimum controller parameter setting that maximizes the minimum damping ratio of the system. On the other hand in this study the goals are control of frequency and inter area tie-power with good oscillation damping and also obtaining a good performance under all operating conditions and various loads and finally designing a low-order controller for easy implementation. The gain values and their respective settling time for both $1 \%$ and $4 \%$ in area 1 and area 2 are given in tables 2,3,4 \& 5 respectively.

\section{Modeling of a Gas turbine}

Amid growing concerns about Green house emissions, Gas turbines have been treated as a viable option, due to their higher efficiency and the lower green house gas emissions compared to other energy sources and fast starting capability which enables them to be often used as peak units that respond to peak demands(Soon klat yee et al, 2008). Also, they can be profitably used in power system restoration for supplying power to the restoration areas as they have the advantages like, Quick start-up/shut-down, Low weight and size, Cost of installation is less, Low capital cost, Black-start capability, High efficiency, Requires low cranking power, Pollutant emission control etc.,

The continuous power plant output of a Gas turbine at the maximum depends upon frequency and temperature. It gives approximately two-thirds of the total power output of a typical combined cycle plant (S. Barsali, et al 2008, M. Nagpal, et al, 2001). When the load is suddenly increased the speed drops quickly, but the regulator reacts and increases the fuel flow to a maximum of $100 \%$ thereby improving the efficiency of the system. A model as shown in fig 2 has been incorporated in the system under study. 


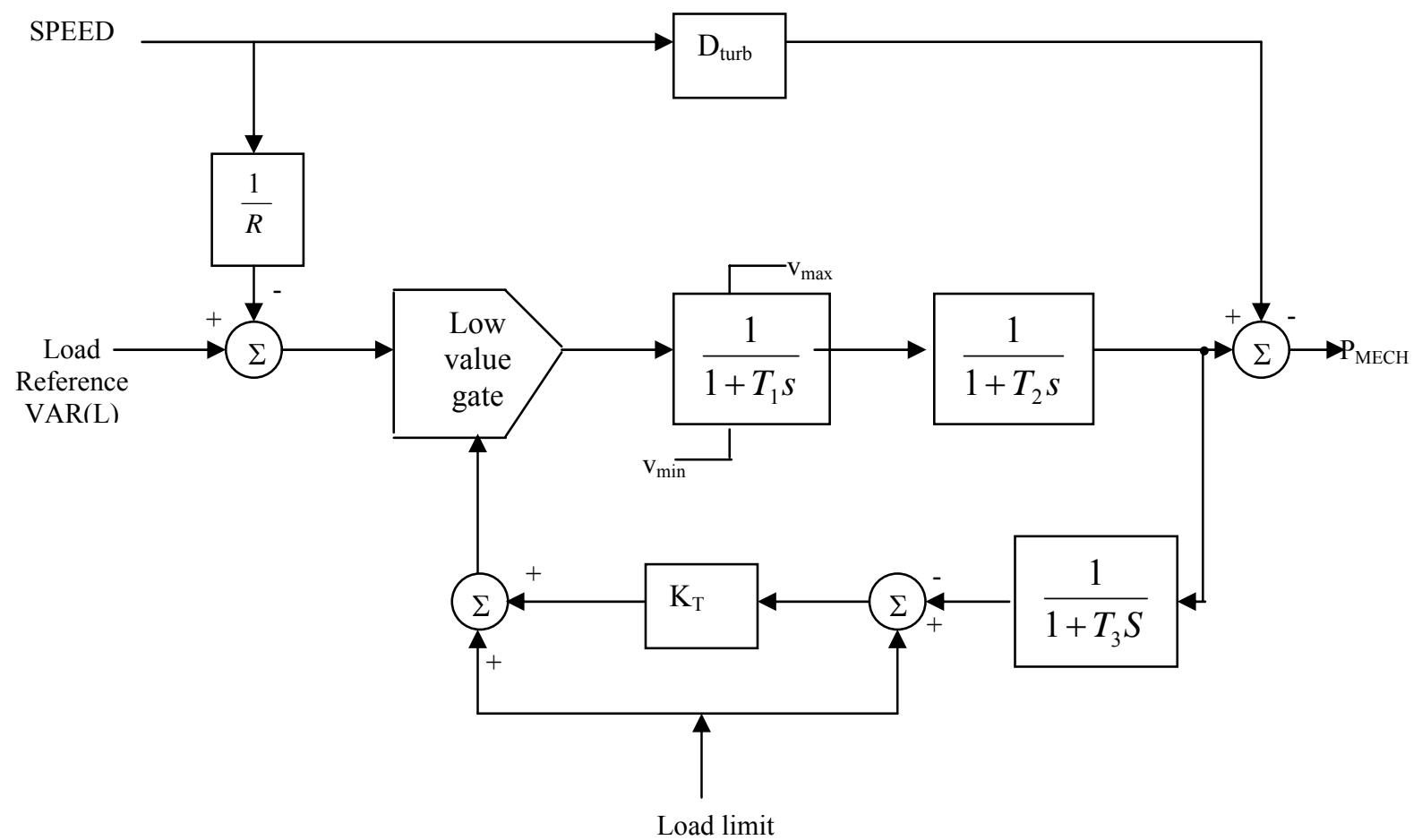

Figure 2. Gas Turbine Model

\section{Super Conducting Magnetic Energy Storage (SMES) device}

The normal operation of a power system is continuously disturbed due to sudden small load perturbations. The problem lies in the fact that the inertia of the rotating parts is the only energy storage capacity in a power system. Thus, when the load-end of the transmission line experiences small load changes, the generators need continuous control to suppress undesirable oscillations in the control to suppress undesirable oscillations in the system. The superconducting magnetic energy system is a fast acting device which can swallow these oscillations and help in reducing the frequency and tie-line Power deviations for better performance of system disturbances. The SMES is designed to store electric energy in the low loss superconducting coil. Power can be absorbed or released from the coil according to the system requirement. A SMES which is capable of controlling active and reactive power simultaneously has been expected as one if the most effective stabilizers for power oscillations (A. Demiroren 2002). Besides oscillation control, a SMES allows a load leveling, a power quality improvement and frequency stabilization. A typical SMES system includes three parts namely superconducting coil, power conditioning system and cooled refrigerator. From the practical point of view, a SMES unit with small storage capacity can be applied not only as a fast compensation device for power consumptions of large loads, but also as a robust stabilizer for frequency oscillations.

\subsection{SMES UNIT:}

The schematic diagram in Fig. 3 shows the configuration of a thyristor controlled SMES unit (S.C. Tripathy, et al, 1997). The SMES unit contains DC superconducting Coil and converter which is connected by $\mathrm{Y}-\mathrm{D} / \mathrm{Y}-\mathrm{Y}$ transformer. The inductor is initially charged to its rated current $\mathrm{I}_{\mathrm{d} 0}$ by applying a small positive voltage. Once the current reaches the rated value, it is maintained constant by reducing the voltage across the inductor to zero since the coil is superconducting $(\mathrm{H}$. Shayegi, et al, 2010). Neglecting the transformer and the converter losses, the DC voltage is given by

$$
\mathrm{E}_{\mathrm{d}}=2 \mathrm{~V}_{\mathrm{d} 0} \cos \alpha-2 \mathrm{I}_{\mathrm{d}} \mathrm{R}_{\mathrm{c}}
$$

Where $E_{d}$ is DC voltage applied to the inductor, firing angle $(\alpha), I_{d}$ is current flowing through the inductor. $R_{c}$ is equivalent commutating resistance and $\mathrm{V}_{\mathrm{d} 0}$ is maximum circuit bridge voltage. Charge and discharge of SMES unit are controlled through change of commutation angle $\alpha$ (A. Demiroren, et al, 2004). 


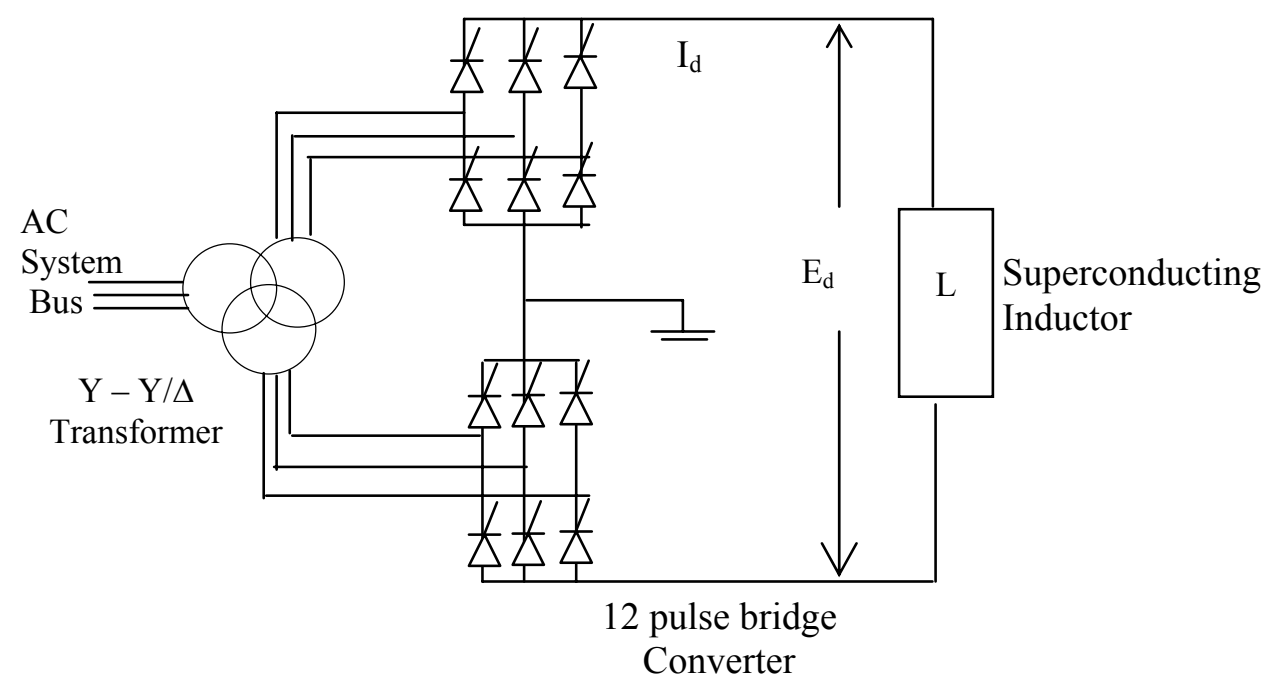

Figure 3. The schematic diagram of SMES unit

In AGC operation, the dc voltage $\mathrm{E}_{\mathrm{d}}$ across the superconducting inductor is continuously controlled depending on the sensed area control error (ACE) signal. Moreover, the inductor current deviation is used as a negative feedback signal in the SMES control loop. So, the current variable of SMES unit is intended to be settling to its steady state value. If the load is used as a negative feedback signal in the SMES control demand changes suddenly, the feedback provides the prompt restoration of current. The inductor current must be restored to its nominal value quickly after a system disturbance, so that it can respond to the next load disturbance immediately. As a result, the energy stored at any instant is given by

$$
\mathrm{W}_{\mathrm{L}}=\mathrm{LI}_{\mathrm{d}}{ }^{2} / 2 \quad \mathrm{MJ}
$$

Where L=inductance of SMES, in Henry

Equations of inductor voltage deviation and current deviation for each area in Laplace domain are as follows

$$
\Delta \mathrm{E}_{\mathrm{di}}(\mathrm{s})=\left(\frac{K_{\text {SMES }}}{1+s T_{\text {dci }}}\right)\left[\beta_{1} \Delta F_{1}(s)+\Delta P_{\text {tie } 1}(s)\right]-\frac{K_{i d}}{1+s T_{d c i}} \Delta I_{d i}(s)
$$

Where

$$
\Delta \mathrm{I}_{\mathrm{di}}(\mathrm{s})=\left(1 / \mathrm{sL}_{\mathrm{i}}\right) * \Delta \mathrm{E}_{\mathrm{di}}(\mathrm{s})
$$

$\Delta \mathrm{E}_{\mathrm{di}}(\mathrm{s})=$ converter voltage deviation applied to inductor in SMES unit

$\mathrm{K}_{\mathrm{SMES}}=$ Gain of the control loop SMES

$\mathrm{T}_{\mathrm{dci}}=$ converter time constant in SMES unit

$\mathrm{K}_{\mathrm{id}}=$ gain for feedback $\Delta \mathrm{Id}$ in SMES unit.

$\Delta \mathrm{I}_{\mathrm{di}}(\mathrm{s})=$ inductor current deviation in SMES unit

The deviation in the inductor real power of SMES unit is expressed in time domain as follows

$$
\Delta \mathrm{P}_{\mathrm{SMESi}}=\Delta \mathrm{E}_{\mathrm{di}} \mathrm{I}_{\mathrm{doi}}+\Delta \mathrm{I}_{\mathrm{di}} \Delta \mathrm{E}_{\mathrm{di}}
$$

Figure 4 shows the block diagram of the SMES unit. To achieve quick restoration of the current, the inductor current deviation can be sensed and used as a negative feed back signal in the SMES control loop. 


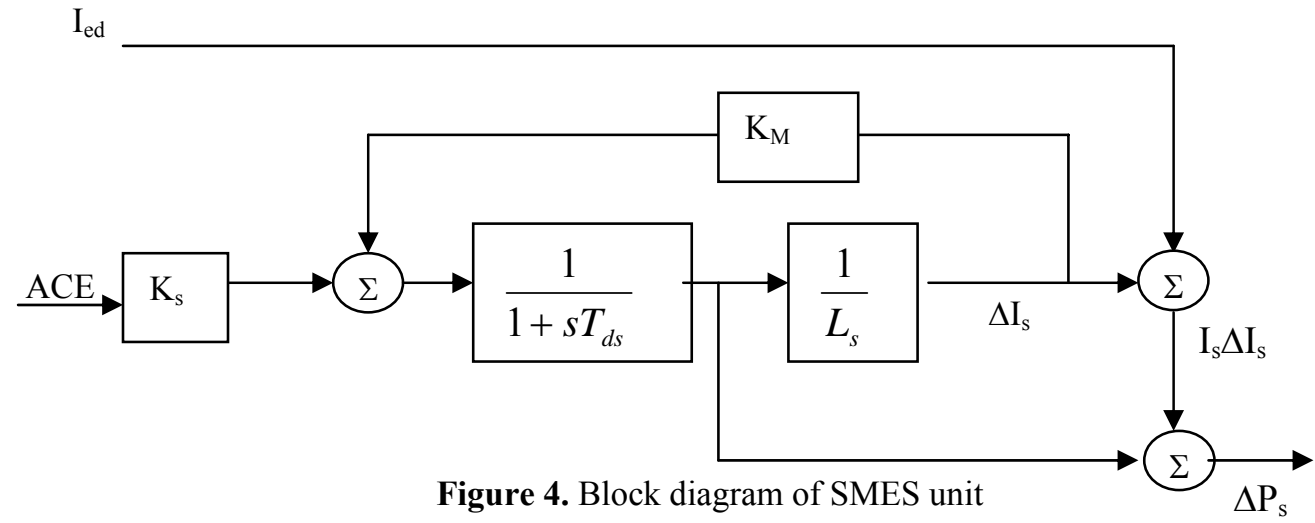

In a two-area interconnected thermal power system under study (as shown in Fig 5) with the sudden small disturbances which continuously disturb the normal operation of power system.

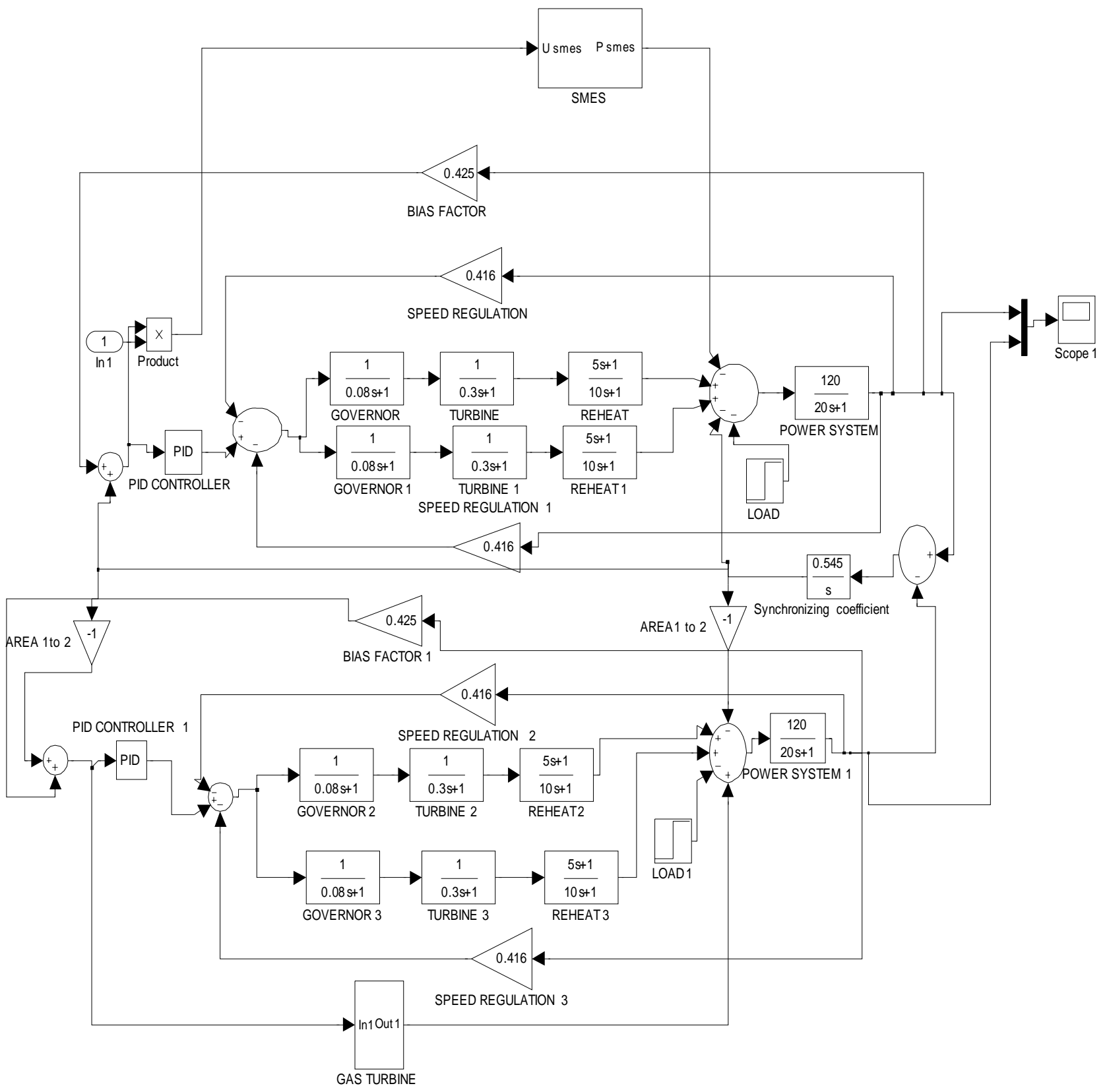

Figure 5. Simulink model of TATURIPS with SMES and Gas Turbine units 
As a result the requirement of frequency controls of areas beyond the governor capabilities SMES is located in area1 absorbs and supply required power to compensate the load fluctuations (Issarachi Nagamroo, 2005, A.Demiroren, et al, 2003, A. Demiroren et al 2004).

Tie-line power flow monitoring is also required in order to avoid the blackout of the power system. The Input of the integral controller of each area is

Where,

$$
\mathrm{ACE}_{\mathrm{i}}=\beta_{\mathrm{i}} \Delta \mathrm{f}_{\mathrm{i}}+\Delta \mathrm{P}_{\text {tie i }}
$$

$\beta_{\mathrm{i}}=$ frequency bias in area $\mathrm{i}$

$\Delta \mathrm{f}_{\mathrm{i}}=$ frequency deviation in area $\mathrm{i}$

$\Delta \mathrm{P}_{\text {tie }}=$ Net tie power flow deviation in area $\mathrm{i}$

The application of energy storages to electrical power system can be grouped into two categories.

1. like conventional pumped hydro plant storage meant for load leveling application.

2. To improve the dynamic performance of power system.

SMES have the following advantages like: The time delay during charge and discharging is quite short, Capable of controlling the both active and reactive power simultaneously, Loss of power is less, High reliability, High efficiency.

\section{Controller design using particle swarm optimization technique for the power system restoration problem}

- This is a population based search technique

- Each individual potential solution in PSO is called particle.

- Each particle in a swarm fly around in a multidimensional search space based on its own experience and experience by neighboring particles

- Let in search space ' $S$ ' in n-dimension with the swarm consists of ' $N$ ' particles

Let, at instant' $t$ ', the particle ' $i$ ' has its position defined by

$X_{t}^{i}=\left\{x_{1}^{i}, x_{2}^{i}, \quad . \quad . \quad . x_{n}^{i}\right\}$

Velocity $V_{t}^{i}=\left\{v_{1}^{i}, v_{2}^{i}, \ldots . \quad . v_{n}^{i}\right\}$ in variable space ' $S$ '

- Velocity and position of each particle in the next generation (time step) can be calculated as

$$
\begin{aligned}
& V_{t+1}^{i}=\omega V_{t}^{i}+C_{1} \cdot \text { rand (). }\left(P_{t}^{i}-X_{t}^{i}\right)+C_{2} \text { Rand ( ) }\left(P_{t}^{g}-X_{t}^{i}\right) \\
& X_{t+1}^{i}=X_{t}^{i}+V_{t+1}^{i}
\end{aligned}
$$

where $\quad N$-number of particle in swarm

$\omega$ - inertia weight

$C_{1}, C_{2}$ - acceleration constant

rand ( ) Rand ( ) - Uniform random value in the range [0,1]

$P_{t}^{i}$ - best-position that particle ' $i$ ' could find so far

$P_{t}^{g}$ - global best at generation ' $\mathrm{t}$ '

- Performance of PSO depends on selection of inertia weight ( $\omega$ ), Max velocity $V_{\max }$ and acceleration constant

$$
\left(C_{1}, C_{2}\right)
$$

- Effect of

\section{- Inertia weight $(\omega)$}

- Suitable weight factor helps in quick convergence

- Large weight factor facilitates global exploration (i.e. searching of new area)

- While small weight factor facilitates local exploration (so wise to choose large weight factor for initial iterations and gradually smaller weight factor for successive iterations)

- Generally, $\omega 0.9$ at beginning and 0.4 at end (Y. Shi et al, 1998)

\section{- Max velocity $V_{\max }$}

- With no restriction on the max velocity of the particle, velocity may become infinitely large.

- If $V_{\max }$ is very low particle may not explore sufficiently 
- If $V_{\max }$ is very high it may oscillate about optimal solution. Therefore, velocity clamping effect has to be introduced to avoid 'swarm explosion' (J. Kennady et al, 2001)

- Generally, max velocity is set as $10-20 \%$ of dynamic range of each variable.

- Velocity can be controlled within a band

$$
V_{\text {max }}=V_{i n i}-\frac{V_{\text {ini }}-V_{f i n}}{\text { iter }_{\text {max }}} \text { iter }
$$

- Acceleration constant $\left(C_{1}, C_{2}\right)$

- $C_{1}$ is called Cognitive Parameter which pulls each particle towards local best position.

- $C_{1}, C_{2}$ is called Social Parameter which pulls the particle towards global best position.

- Generally, $C_{1}, C_{2}$ are chosen between 0 to 4

The design steps of PSO based PI controller is as follows.

1. The algorithm parameters like number of generation, population, inertia weight and constants are initialized.

2. The values of the parameters KP and Ki initialized randomly.

3. The fitness function of each particle in each generation is calculated.

4. The local best of each article and the global best of the particles are calculated.

5. The position, velocity, local best and global best in each generation is updated

6. Repeat the steps 3 to 5 until the maximum iteration reached or the best solution is found.

\subsection{Simulink model of PSO Based PI Controller}

Figure 6. shows the simulink model of the plant with PSO algorithm based PI controller.The PSO algorithm is used to search an optimal parameter set containing $\mathrm{K}_{\mathrm{p}}$ and $\mathrm{K}_{\mathrm{i}}$. The parameters used for tuning the PSO algorithm and simulink models are tabulated in table below and Fig. 7 represents the corresponding flow chart:

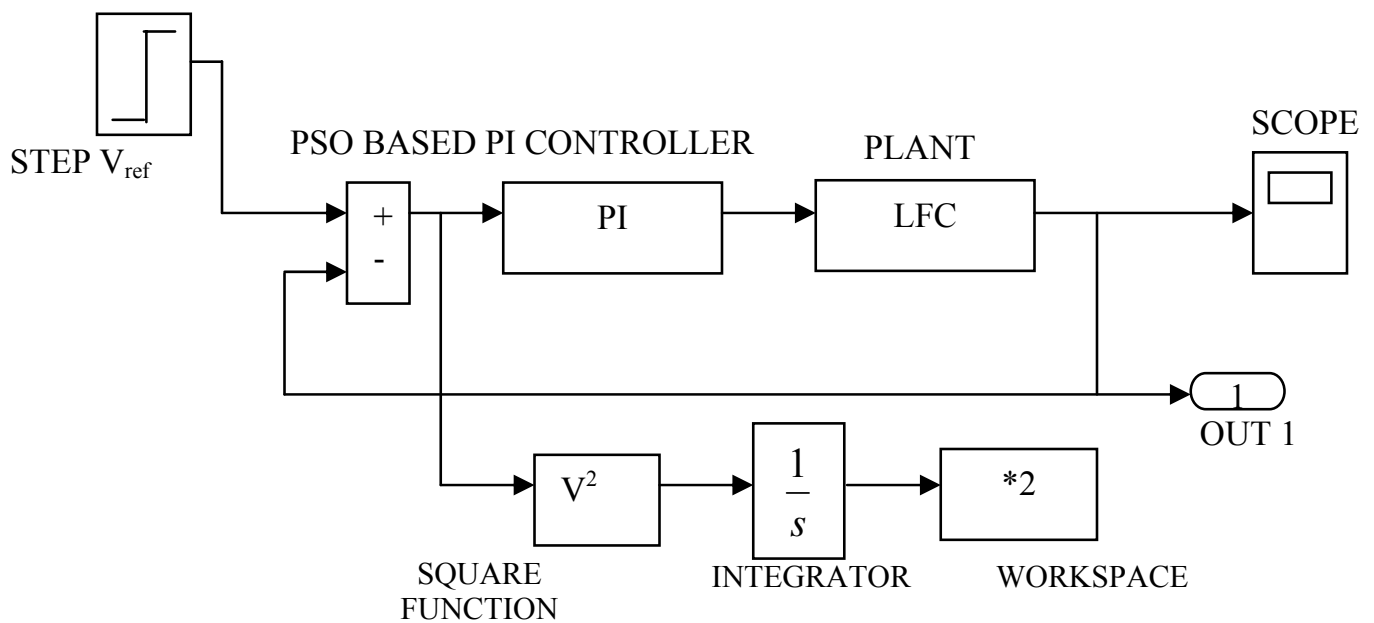

Figure 6. Simulink model of plant with PSO Algorithm based PI Controller

Table 1. Parameter values tuned for PSO algorithm

\begin{tabular}{|l|l|}
\hline Parameters & Value \\
\hline Population size & 5 \\
\hline Number of generations & 10 \\
\hline Inertia weight $(\omega)$ & 0.8 \\
\hline cognitive coefficient $(\mathrm{C} 1)$ & 2.05 \\
\hline social coefficient $(\mathrm{C} 2)$ & 2.05 \\
\hline
\end{tabular}




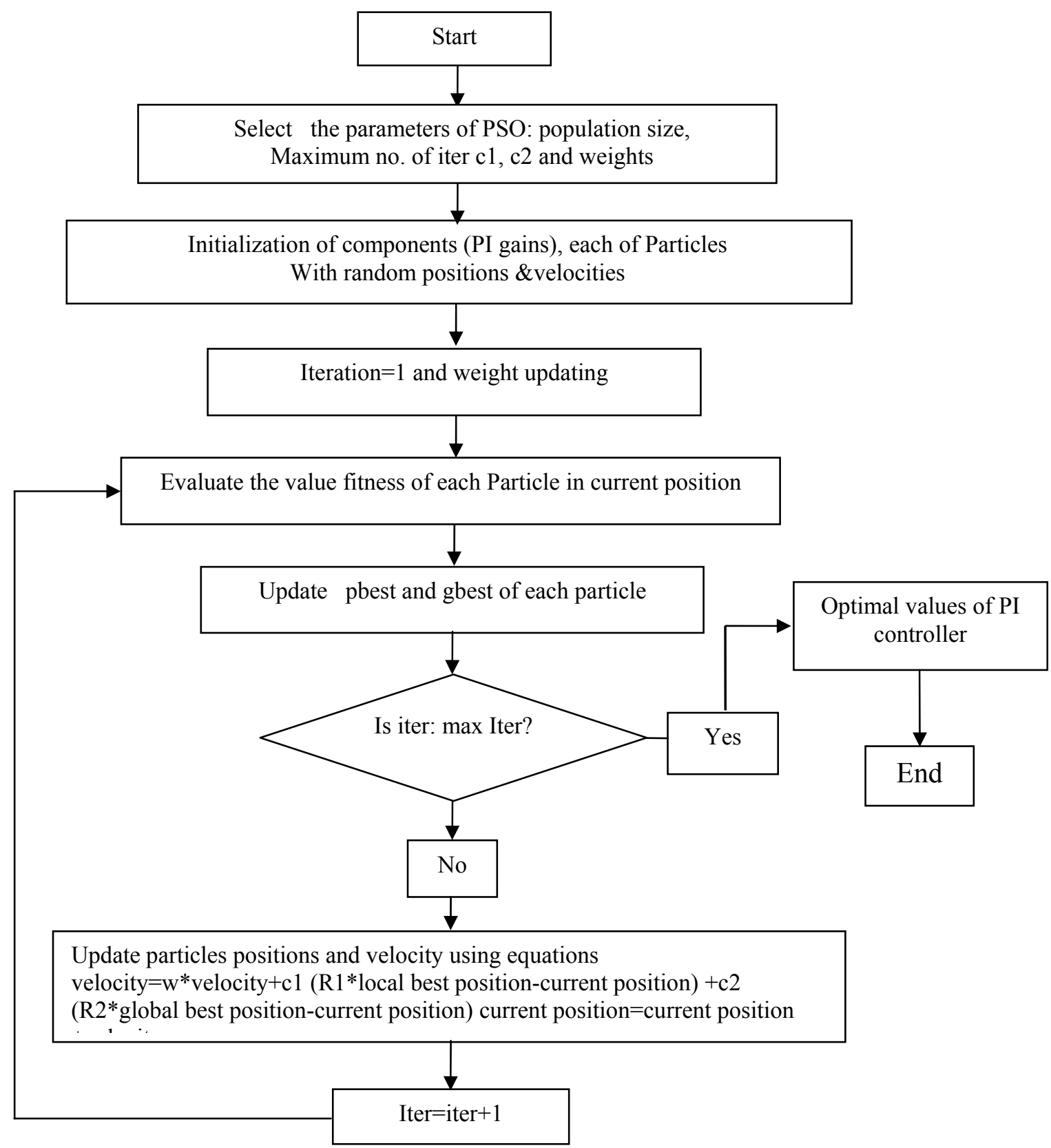

Figure 7: Flowchart for PSO

Table 2. Proportional plus Integral controller gains for 0.01p.u. MW step-load change in Area-2

\begin{tabular}{|l|c|c|}
\hline \multirow{2}{*}{ Power system } & \multicolumn{2}{|c|}{ Gain values } \\
\cline { 2 - 3 } & $\mathbf{K}_{\mathbf{P}}$ & $\mathbf{K}_{\mathbf{I}}$ \\
\hline Conventional in Area1 \& 2 & 0.95 & 0.30 \\
\hline With SMES in Area-1 & 0.52 & 0.26 \\
\hline With GT in Area-2 & 0.65 & 0.24 \\
\hline
\end{tabular}


CASE 1: Comparison of frequency deviations, control input requirements and tie-line power deviations in a two-area interconnected thermal reheat power system for 0.01p.u. MW load change in area-2.

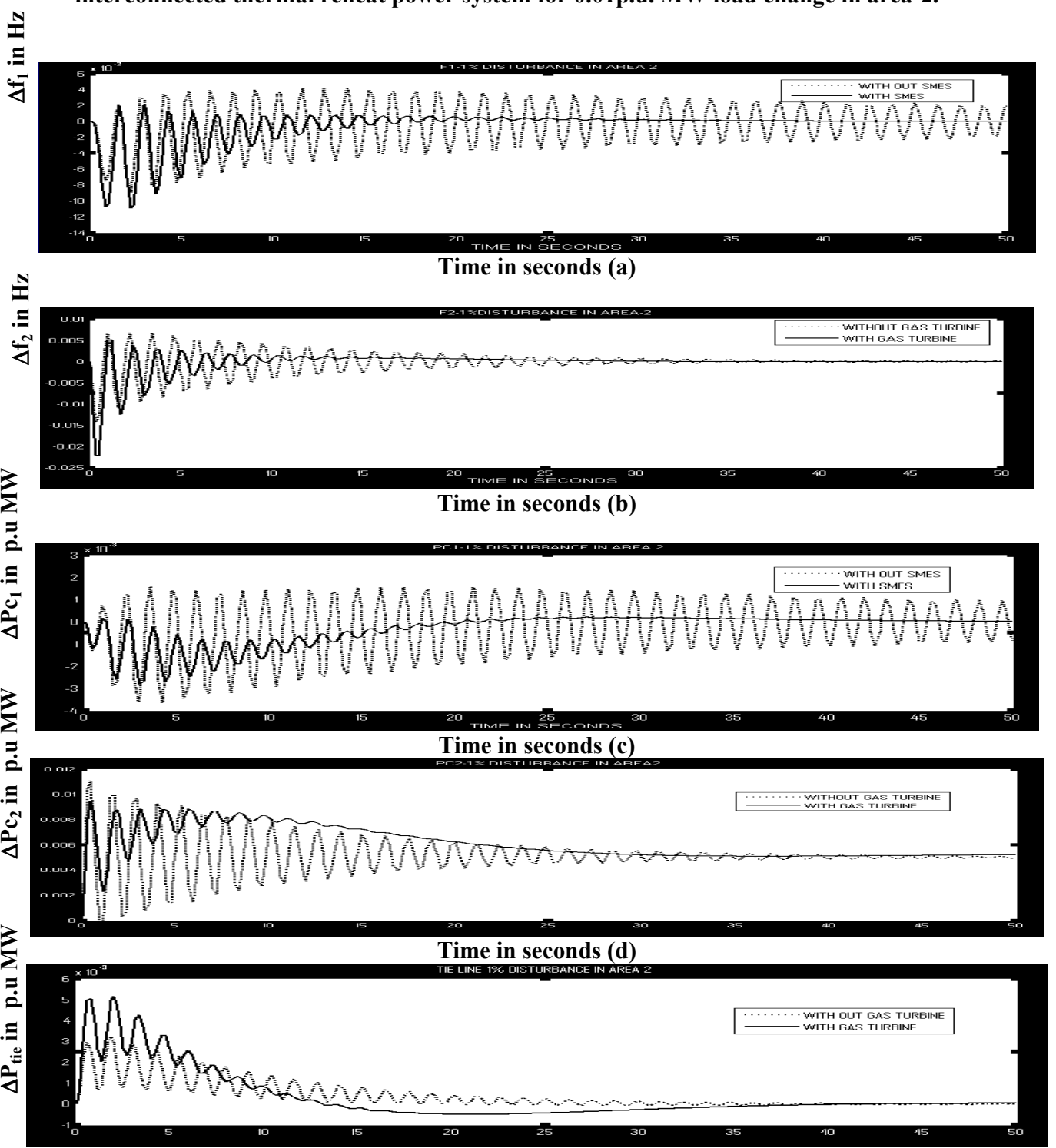

Time in seconds (e)

(a) Frequency deviation without and with SMES

(b) Frequency deviation without and with Gas Turbine

(c) Control input requirement without and with SMES

(d) Control input requirement without and with Gas Turbine

(e) Tie-line power deviations without and with Gas Turbine

Table 3: Settling Time (in seconds) of the output response without and with GT For 0.01p.u. MW step load change in area-2

\begin{tabular}{|l|l|l|}
\hline \multicolumn{1}{|c|}{ Power System } & \multicolumn{1}{|c|}{ Change in frequency H.Z } & \multicolumn{1}{c|}{$\Delta$ Ptie $_{\mathbf{1}}$} \\
\hline Without GT & More than 45 sec. $\left(\Delta \mathrm{F}_{2}\right)$ & More than $50 \mathrm{sec}$ \\
\hline With GT in area-2 & $13 \mathrm{sec} .\left(\Delta \mathrm{F}_{2}\right)$ & $12 \mathrm{sec}$ \\
\hline Without SMES & More than $50 \mathrm{sec} .\left(\Delta \mathrm{F}_{1}\right)$ & More than $50 \mathrm{sec}$ \\
\hline With SMES in area-1 & $25 \mathrm{sec} .\left(\Delta \mathrm{F}_{1}\right)$ & $13 \mathrm{sec}$. \\
\hline
\end{tabular}


Table 4: Proportional plus Integral controller gains for 0.04 p.u. MW step-load change in Area-2

\begin{tabular}{|l|l|c|}
\hline \multirow{2}{*}{ Power system } & \multicolumn{2}{c|}{ Gain values } \\
\cline { 2 - 3 } & $\mathbf{K}_{\mathbf{P}}$ & $\mathbf{K}_{\mathbf{I}}$ \\
\hline Conventional in Area 1 \& 2 & 0.98 & 0.22 \\
\hline With SMES in Area-1 & 0.64 & 0.15 \\
\hline With GT in Area-2 & 0.7 & 0.26 \\
\hline
\end{tabular}

CASE 2: Comparison of frequency deviations, control input requirements and tie-line power deviations in a two-area interconnected thermal reheat power system for 0.04p.u. MW load change in area-2.

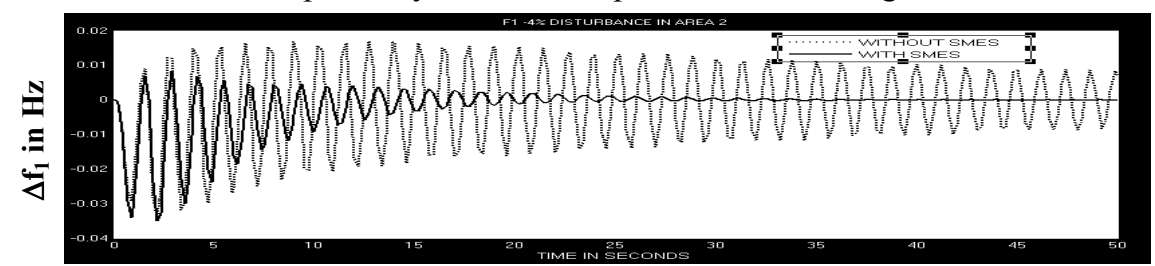

Time in seconds (a)

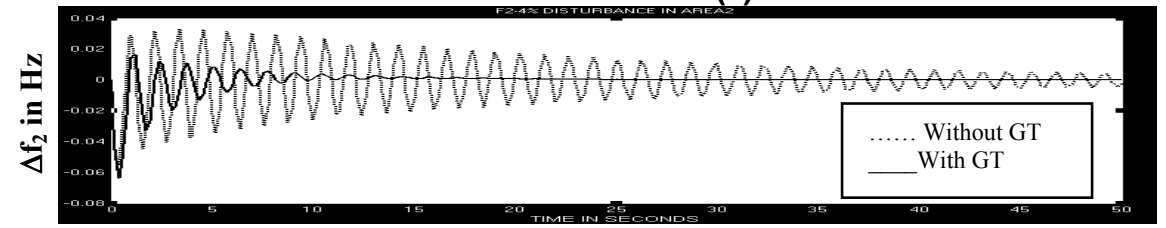

Time in seconds (b)

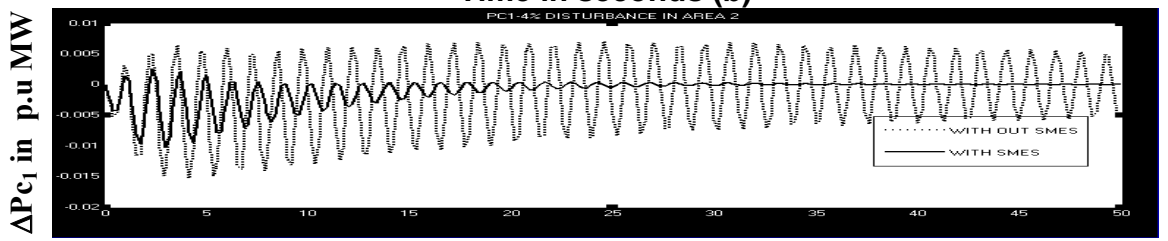

Time in seconds (c)

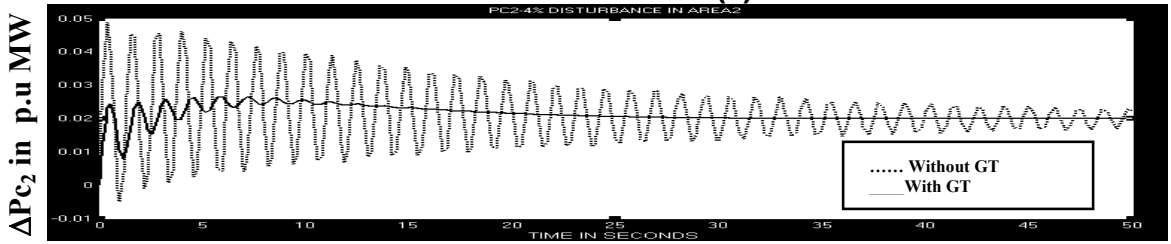

Time in seconds (d)

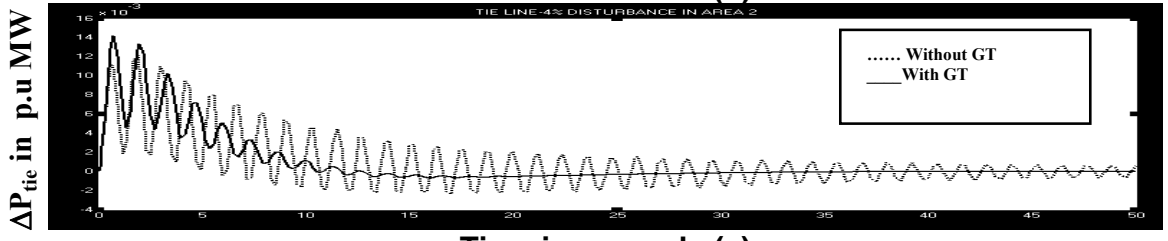

Time in seconds (e)

(a) Frequency deviation without and with SMES

(b) Frequency deviation without and with Gas Turbine

(c) Control input requirement without and with SMES

(d) Control input requirement without and with Gas Turbine

(e) Tie-line power deviations without and with Gas Turbine

Table 5: Settling Time (in seconds) of the output response without and with GT For 0.04p.u. MW step load change in area-2

\begin{tabular}{|l|l|l|}
\hline \multicolumn{1}{|c|}{ Power System } & \multicolumn{1}{|c|}{ Change in frequency H.Z } & \multicolumn{1}{c|}{$\Delta$ Ptie $_{\mathbf{1}}$} \\
\hline Without GT & More than $45 \mathrm{sec} .\left(\Delta \mathrm{F}_{2}\right)$ & More than $50 \mathrm{sec}$ \\
\hline With GT & $12 \sec \left(\Delta \mathrm{F}_{2}\right)$ & $13 \mathrm{sec}$ \\
\hline Without SMES & More than $50 \mathrm{sec} .\left(\Delta \mathrm{F}_{1}\right)$ & More than $50 \mathrm{sec}$ \\
\hline With SMES & $35 \mathrm{sec} .\left(\Delta \mathrm{F}_{1}\right)$ & $18 \mathrm{sec}$. \\
\hline
\end{tabular}




\section{Conclusion}

In this work a novel heuristic search technique (i.e.) PSO based controllers are designed and implemented in a two-area two-unit thermal reheat power system with GT in area 2 and SMES in area 1 by optimizing the gain values of the PI controller to restore the frequency and tie-line power deviations due to various step-load changes in area 2 . The output response of the system reveals that reduced peak overshoots, minimum settling time are obtained thereby maintaining the stability of the system under study to greater extent when comprised with GT unit. Using this global optimization controller the improvement of the dynamic performance of TATURIPS is found to be very clear in attaining the restoration of the system under consideration. The proposed controller yields good transient response with a minimum settling time. Further, this work is being extended with the consideration of the system non-linearities.

\section{APPENDIX}

Data for the two-area interconnected thermal power system with reheat turbines (Chidambaram I.A et al., 2005)

$$
\begin{aligned}
& \operatorname{Pr}_{1}=\mathrm{Pr}_{2}=2000 \mathrm{MW} \\
& \mathrm{Kp}_{1}=\mathrm{Kp}_{2}=120 \mathrm{~Hz} / \mathrm{p} . \mathrm{u} \\
& \mathrm{Tp}_{1}=\mathrm{Tp}_{2}=20 \mathrm{sec} . \\
& \mathrm{Tt}_{1}=\mathrm{Tt}_{2}=0.3 \mathrm{sec} . \\
& \mathrm{Tg}_{1}=\mathrm{Tg}_{2}=0.08 \mathrm{sec} . \\
& \mathrm{Kr}_{1}=\mathrm{Kr}_{2}=0.5 \\
& \mathrm{Tr}_{1}=\mathrm{Tr}_{2}=10 \mathrm{sec} . \\
& \mathrm{R}_{1}=\mathrm{R}_{2}=2.4 \mathrm{~Hz} / \mathrm{p} . \mathrm{u} \mathrm{MW} . \\
& \mathrm{a}_{12}=-1 \\
& \mathrm{~T}_{12}=0.545 \text { p.u MW } / \mathrm{Hz} \\
& \beta_{1}=\beta_{2}=0.425 \text { p.u. } \mathrm{MW} / \mathrm{Hz}
\end{aligned}
$$

Data for the SMES unit (Demiroren.A 2002)

$$
\begin{aligned}
& \mathrm{L}=2.65 \mathrm{H} \\
& \mathrm{T}_{\mathrm{dc}}=0.03 \mathrm{sec} \\
& \mathrm{I}_{\mathrm{do}}=4.5 \mathrm{KA} \\
& \mathrm{K}_{\mathrm{id}}=0.2 \mathrm{KV} / \mathrm{KA} \\
& \mathrm{K}_{\mathrm{SMES}}=100 \mathrm{KV} / \text { unit } \mathrm{MW}
\end{aligned}
$$

Data for the Gas turbine model (Soon klat yee et al., 2008)

$$
\begin{aligned}
& \mathrm{T}_{1}=10 \mathrm{sec} \\
& \mathrm{T}_{2}=0.1 \mathrm{sec} \\
& \mathrm{T}_{3}=3 \mathrm{sec} \\
& \mathrm{K}_{\mathrm{t}}=1 \\
& \mathrm{~K}_{\mathrm{r}}=0.04 \\
& \text { Dturb }=0.03
\end{aligned}
$$

Maximum and minimum valve position $=1$ and -0.1

\section{Acknowledgement}

The authors wish to thank the authorities of Annamalai University, Annamalai Nagar, Tamilnadu, India for the facilities provided to prepare this paper.

\section{References}

Adibi M.M., R.J Kafka,D.P Milanic,Aug 1994 Expert system requirements for power system Restoration, IEEE Transactions on Power Systems, Vol.9, pp.1592-1598.

Aldeen, M. and J.F. Marsh, 1991. Decentralized PI design method for interconnected power systems. IEE Proc.-C, Vol. 138,263274, No. 4.

Barsali S., D. Poli, A.Pratico, R.Salvati, M.Sforna, Aug 2008, Restoration islands supplied by gas turbine, Electrical Power System Research, Vol. 78, pp. 2004-2010.

ChaoOu, Weixing Lin, June 2006, Comparison between PSO and GA for parameters optimization of PID Controller, Proceedings of the IEEE International Conference on Mechatronics and Automation, pp. 2471-2475.

Chidambaram I.A. and S.Velusami, 2005, Design of decentralized biased controllers for load-frequency control of interconnected power systems, Electric Power Components and Systems, Vol. 33, No.12, pp.1313-1331. 
Demiroren A., 2002 Application of a self-tuning to power system with SMES, European Transactions on Electrical Power (ETEP), Vol. 12, No. 2, pp. 101-109.

Demiroren A., 2003 AGC for power system with SMES by using NN controller, Electric Power Components and Systems, Vol. 31, No. 1, pp. 1-25.

Demiroren A., HL Zeynelail Sengor, 2004, AGC using ANN technique for multi-area power system with SMSE unit, Electric Power Components and Systems, Vol. 32, pp. 193-213.

Demiroren and E. Yesil, "Automatic generation control with fuzzy logic controllers in the power system including SMES units", Electrical Power \& Energy Systems, Vol.26, No.4, pp. 291-305, May 2004.

Ghoshal S.P., June 2004, Optimizations of PID gains by particle swarm optimizations in fuzzy based automatic generation control, Electrical Power System Research, Vol.2, pp.203-212.

Issarachai Ngamroo, 2005, Robust decentralized frequency stabilizers for SMES taking into consideration system uncertainties, Electric Power System Research, Vol. 74, No. 2, pp. 281-292.

Kennady, J. and R.C. Eberhart, 1995, Particle swarm optimization. In: Proc. IEEE Int. Conf. on Neural Network, Perth, Australia, pp: 1942-1948.

Kennady J., R.C. Eberhart and Y.Shi, "Swarm Intelligence”, Morgan Kaufmann, San Francisco, 2001.

Lim, K.Y. et al., 1996. Robust decentralized load frequency control of multi-area power system. IEE Proceedings-C, Vol. 143, No. 5, pp. 377-386.

Nagpal M., A. Moshref, G.K Morision, P.Kundur, Jan 2001, Experience with Testing and modeling of gas turbine, Proceedings of the IEEE/PES 2001 Winter Meeting, Columbus USA, pp. 652-656.

Pan, C.T. and C.M. Liaw, 1989. An adaptive control for power system LFC. IEEE Trans. PWRS, Vol. 4, No. 1, pp. 122-128.

Shayegi H., H.A. Shayanfar and O.P. Malik, 2007. Robust decentralized neural networks based LFC in a deregulated power system. Electric Power System Research, Vol. 77, pp.241-251.

Shayeghi H. et al., 2007. Robust modified GA based multi-stage fuzzy LFC. Energy Conversion and Manag., Vol. 48, pp. 16561670 .

Shayeghi, H., H.A. Shayanfar, 2010. Application of PSO for fuzzy load frequency design with considering superconducting magnetic energy storage, International Journal of TPE, Vol. 1, No. 2, pp. 24-33.

Shi Y. and R.C.Eberhart, 1998, Parameter selection in PSO", Proceedings of $7^{\text {th }}$ Annual Conference on Evolutionary Computation, pp.591-601.

Soon Klat Yee, Jovica, F.Michael Hughcs, Feb 2008, Overview and comparative analysis of gas turbine model for system stability studies, IEEE Transactions on Power Systems, Vol. 23, pp.108-118.

Tripathy S.C., R. Balasubramanian,P.S. Chandramohanan Nair, 1997, Adaptive automatic generation control with superconducting magnetic energy storage in power systems, IEEE Trans. Energy Convers. Vol. 7, No. 3, pp. 434-441.

Wang Y., D.J. Hill and G. Guo, 1998. Robust decentralized control for multi-machine power system, IEEE Trans. on Circuits and Systems: Fund. Theory and Applications., Vol. 45, No. 3, pp. 271-279.

Yamashita K. and H. Miagi, 1991. Multi variable self-tuning regulator for LFC system with interaction of voltage on load demand. IEE Proceeding Conference: Theory and Applications. Vol. 138, No. 2, pp. 177-183.

\section{Biographical Notes}

R. Jayanthi received her B.E and M.E degrees from Faculty of Engineering and Technology, Annamalai University, Annamalai Nagar, Chidambaram, India in 1994 and 2007 respectively. Currently working as an Assistant Professor in Department of Electrical and Electronics Engineering since 2007. She is currently working towards the Ph.D degree. Her research interest includes power system operation and control.

Dr. I. A. Chidambaram (1966) received Bachelor of Engineering in Electrical and Electronics Engineering (1987) Master of Engineering in Power System Engineering (1992) and Ph.D in Electrical Engineering (2007) from Annamalai University, Annamalainagar. During 1988 - 1993 he was working as Lecturer in the Department of Electrical Engineering, Annamalai University and from 2007 he is working as Professor in the Department of Electrical Engineering, Annamalai University, and Annamalai Nagar. He is a member of ISTE and Indian Science Congress (ISC). His research interests are in power systems, electrical measurements and control systems. (Electrical Measurements Laboratory, Department of Electrical Engineering, Annamalai University, Annamalai Nagar-608002, TamilNadu, India, Tel: -91-04144-238501, Fax:-91-04144-238275)driacdm@yahoo.com/driacdm@gmail.com

C. Banusri is currently working as a Lecturer in Jaya College of Engineering, Avadi, Chennai, and received her B.E and M.E. degrees from Mailam Engineering College affiliated to Madras University (2002) and Annamalai University (2010) respectively. Her areas of interest are power system modeling and control.

Received October 2010

Accepted April 2011

Final acceptance in revised form April 2011 